Hatle L, Brubakk A. Tromsdal A, Angelsen B. Noninvasive assessment of pressure drop in mitral enosis by Doppler ultrasound. Br Heart f 1978;40:131-40

Hatle L, Angelsen B, Tromsdal A. Noninvasive assessment of aortic stenosis by Dopple ultrasound. Br Heart $f$ 1980;43:284-92.

Lima CO, Sahn DJ, Valdes-Cruz LM, Barron JV, Allen HD, Grenadier E. Noninvasive prediction of transvalvular pressure gradients in patients with pulmonary stenosis by quantitative twodimensional echocardiographic Doppler studies. Circulation 1983;67:866-71.

+ Simpson IA, Houston AB, Sheldon CD. Hutton I, Lawrie TDV. Clinical value of Doppler echocardiography in adults with aortic stenosis. Br Heart $f$ 1985:53:636-9.

Currie PJ, Seward JB, Reeder GS, et al. Continuous-wave Doppler echocardiographic assessment of severity of calcific aortic stenosis: a simultaneous Doppler-catheter correlative study in 100 adult patients. Circulation 1985:71:1162-9.

Sahn DJ. Real-time two-dimensional echo Doppler flow mapping. Circulution 1985;71:849-53.

Omoto R, Yokote Y, Takamoto S, et al. The development of real-time two-dimensional Dopple

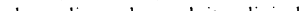
cecence

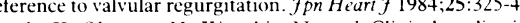

. Kinoshita $\mathrm{N}$ et al Clinical applications of a new tupe of real-time two dimensional flow imaging system. Am 7 Cardiol 1984:54:857-68

9 Hornberger LK, Sahn DJ, Krabill KA, et al. Elucidation of the natural history of ventricular septal defects by serial Doppler color flow mapping studies. F Am Coll Cardiol 1989;13:1111-8.

10 Miyatake K, Izumi S, Okamoto M, et al. Semiquantitative grading of severity of mitra regurgitation by real-time two-dimensional Doppler flow imaging technique. $7 \mathrm{Am}$ Coll Cardiol $1986 ; 7: 82-8$.
1 Helmcke F, Nanda NC, Hsuing MC, et al. Color Doppler assessment of mitral regurgitation with orthogonal planes. Circulation 1987:75:175-83.

2 Otsuij Y, Tei C, Kisanuki A, Natsugoe K, Kawazoe Y. Color Doppler echocardiographic assessment of the change in the mitral regurgitant volume. Am Heart 7 1987:114:349-54.

3 Davidoff $R$, Wilkins GT, Thomas JD, Achorn DM. Weyman AE. Regurgitant volumes by cotor flow overestimate injected volumes in an in vitro model 7 . A $m$ Coll Cardiol 1987;9:110A.

14 Switzer DF, Yoganathan AP, Nanda NC, Woo Y, Ridgeway AJ. Calibration of color Doppler flow mapping during extreme hemodynamic conditions in vitro: a foundation for a reliablc quantitative grading ststem for aortic incompetence. Circulation 1987:75:837-46.

5 Simpson IA, Valdes-Cruz LM, Sahn DJ. Murillo A, Tamura T, Chung KJ. Doppler color flow mapping of simulated in vitro regurgitant jets: Evaluation of the effects of orifice size and hemodynamic variables. 7 A $m$ Coll Curdiol 1989;13:1195-207.

16 Smith MD, Gravburn PA, Spain MG, DeMaria AN. Observer variability in the quantitation of Doppler color flow jet areas for mitral and aortic regurgitation. I Am Coll Cardol 1988:11:579.

17 Sahn DJ, Maciel BC. Physiological valvular regurgitation: Doppler echocardiography and the potential for iatrogenic heart disease. Circulation 1988:78:1075-7.

18 Jones M. Eidbo EE. Doppler color flow evaluation of prosthetic mitral valves: experimental epicardial studies. 7 . Am Coll Cardiol 1989:13:234-40.

19 Simpson IA, Valdes-Cruz LM, Yoganathan AP, Sung HW, Jimoh A, Sahn DJ. Spatial velocity distribution and acceleration in serial subvalve tunnel and valvular obstructions: an in vitro study using Doppler color flow mapping. I A $m$ Coll Cardiol 1989:13:241-8.

\title{
Prophylactic antibiotics and caesarean section
}

\section{Important role but not necessarily always}

In Britain, as elsewhere, the caesarean section rate has increased, and in the face of pressures from litigation it is unlikely to decline. ${ }^{1}$ Postoperative infection is an important complication, causing immediate and chronic abdominal pain, impairing fertility, and, in severe cases, threatening the mother's life. Antibiotic prophylaxis during caesarean section has been subjected to many controlled trials ${ }^{2}$ but has not found widespread favour in Britain, ${ }^{3+}$ though it is used more extensively in the United States.

The National Perinatal Epidemiology Unit in Oxford has recently carried out a meta-analysis of the randomised controlled trials of the value of antibiotic prophylaxis at the time of caesarean section. ${ }^{2}$ No fewer than 16000 patients were included, and wound infection was usually defined as either a positive bacterial culture or the presence of frank pus. ${ }^{6}$ In the groups given placebo or no treatment the mean incidence of this was $9 \%$, corresponding to that of $6-14 \%$ in a recent national study. ${ }^{+}$Although more difficult to measure, other indicators of postoperative infection include postoperative febrile illness ${ }^{7}$ and endomyometritis, ${ }^{8}$ and the meta-analysis found average rates in untreated mothers of $40 \%$ and $26 \%$ respectively. Serious postoperative infections, such as pelvic abscess and septicaemia, were less common but still developed in an appreciable number of patients.

In contrast to these figures, mothers who had received antibiotic prophylaxis had infection rates of about one third of those in the untreated controls. This proportionate reduction occurred for all the outcome measures studied in the meta-analysis, with the confidence intervals showing high significance. These results point strongly to the conclusion that antibiotic prophylaxis should be considered in caesarean section.

What the meta-analysis does less precisely, however, is to say how policies should be developed for individual mothers. It is not yet certain whether antibiotic prophylaxis should be given to all mothers having caesarean sections or to those at greatest risk. Several factors - such as the duration of labour and prolonged rupture of the membranes - carry an increased risk of postoperative infection so that mothers having an emergency caesarean section may gain more than those having an elective procedure. ${ }^{510}$ Other important factors are the timing and route of giving antibiotics, ${ }^{5}$ for a central principle of prophylaxis is that peak tissue concentrations should be achieved when the bacteraemia is highest. " Nevertheless, systemic administration of the antibiotic can be delayed until after the cord has been clamped without loss of efficacy. ${ }^{12}$ This policy, now the one most widely adopted, avoids any antibiotic reaching the neonate. Local administration of antibiotic has been tried but has little to offer over intravenous injection during surgery. ${ }^{5}$ Possibly multiple doses will be more effective than single ones, although multiple doses will be more complex to arrange, more costly, and more likely to cause side effects. ${ }^{13}$ The results of comparative studies suggest that broad spectrum penicillins and cephalosporins are equally effective, ${ }^{8}$ and that adding metronidazole will not increase their potency. ${ }^{2}$

No harm should result from any prophylactic regimen, and the most immediate risk is anaphylaxis: two deaths have occurred with antibiotic prophylaxis after operations (not caesarean sections). ${ }^{14}$ Provided there is no history of allergy the risk of such tragedies is low and has to be balanced against that of death from preventable infection after caesarean section. ${ }^{2}$ Another concern is the development of resistant strains of organisms in maternity hospitals, ${ }^{1015}$ an important argument in limiting the use of prophylactic antibiotics. ${ }^{3}$ If antibiotic prophylaxis becomes more widespread we shall need to monitor mothers who develop infection despite prophylaxis for resistant strains as well as the patterns of resistance among the hospital flora at regular intervals. ${ }^{10}$

The Oxford group, however, has taken the argument a stage further, suggesting that prophylactic antibiotics at the time of caesarean section would be cost effective. ${ }^{16}$ They argue that the cost of prophylactic antibiotics would be more than compensated by savings in staff time, inpatient stay, and the cost of therapeutic antibiotics. Several similar hypothetical analyses of the costs of hospital acquired infection have been put forward, ${ }^{17-19}$ and the Oxford group's hypothesis must be tested prospectively in a controlled trial. The major cost of hospital infection is prolonged hospital stay and even the most careful case-control study leaves the possibility that the infection and the prolonged stay both result from other factors in the patient's condition. For example, in a prospective study of gynaecological surgery cephradine prophylaxis for abdominal hysterectomy reduced costs to the hospital and the community health services with measurable improvement in the patients' rate of recovery..$^{20}$ Nevertheless, there was no significant difference in length of hospital stay between the groups given prophylaxis or placebo. Moreover, the same study found that prophylaxis for vaginal hysterectomy did not reduce hospital stay or improve the recovery rate, despite 
reducing the infection rate. Resources may be wasted through introducing measures to control infection that are either ineffective or used inefficiently. ${ }^{17}$ Although antibiotic prophylaxis for caesarean section reduces the risk of infection, ${ }^{28}$ savings to the hospital or benefits to the patient have not been fully measured.

The evidence suggests that prophylactic antibiotics have an important place in preventing infection after caesarean section. Nevertheless, every effort must be made to avoid unnecessary operations and to ensure optimum surgical technique. Further studies are required to define which patients are most suitable for prophylaxis, the best choice of antibiotics, the optimum dosage regimen, and the potential risks of resistant organisms.

P W HOWIE Professor of Obstetrics and Gynaecology

PG DAVEY

Senior Lecturer in Clinical Pharmacology and Infectious Diseases

University of Dundee,

Ninewells Hospital and Medical School,

Dundee DD1 9SY
McIlwaine GM, Cole SK, Macnaughton MC. The rising caesarean section rate-a matter of concern? Health Bulletin 1985;7:301-5.

2 Enkin $M$, Enkin E, Chalmers I, Hemminki E. Antibiotics and caesarean section. In: Chalmers I, Enkin $M$, Keirse $M J N C$, eds. Effectize care in pregnancy and childbirth. Oxford: Oxfor University Press, 1989:1246-69.

3 Anonymous. Prophylactic antibiotics in caesarean section [Editorial]. Br Med f 1973;ii:675-6. + Moir/Bussey BR, Hutton R.M. Thompson R. Wound infection after cacsarean section. f Hosp Infect 1984:5:359-70

Duff P. Prophllactic antibiotics for caesarean deliverv. A simple cost-effective strategy for prevention of postoperative morhidity. Am f Obstet Gynecol 1987;157:794-8.

6 Pelle $\mathrm{H}$, Jepsen $\mathrm{OB}$, Larsen $\mathrm{SO}$, et al. Wound infection after caesarean section. Infect Control $1986 ; 7: 456-61$.

Cunningham FG, Hauth JC, Strong JD,

section. Obstet Gunceol 1978.52:656-61.

artz WH, Grolle K. The use of prophylactic antibiotics in caesarean section. 7 Reprod Med 1981:26:595-609.

9 Green SL Sarubbi FA, Bishop FH. Prophylactic antibiotics in high-risk caesarean section Obstet Gynecol 1978:51:569-72.

0 Galask RP. Changing concepts in obstetric antibiotic prophylaxis. Am 7 Obstet Gynecol 1987; 157:491-7.

11 Burke JF. Preventive antibiotic management in surgery. Annu Rev Med 1973;24:289-94.

12 Gordon HR, Phelps D, Blanchard K. Prophylactic caesarean section antibiotics: maternal and neonatal morbidity before or after cord clamping. Obstet Gynecol 1979;53:151-6.

13 Iams JD, Chawla $\mathrm{A}$. Patient costs in the prevention and treatment of post-caesarean section infection. Am f Obstet Gynecol 1984;149:363-6.

14 Spruill FG, Minette LJ, Sturner WQ. Two surgical deaths associated with cephalothin. FAMA 1974:229:440-1

15 Gibbs RS, Clair PJ, Castillo MS, Castaneda YS. Bacteriologic effects of antibiotic prophylaxis in high-risk caesarean section. Obstet Gynecol 1981:57:277-82

16 Mugford M, Kingston J, Chalmers I. Reducing the incidence of infection after caesarean section: implications of prophylaxis with antibiotics for hospital resources. Br.Med 7 1989:299:1003-6.

17 Currie $\mathrm{E}$ Maynard A Economic aspects of hospital acquired infections York: Centre for Health Economics, University of York, 1989. (Discussion paper 56.

\section{Cancer of the oesophagus}

\section{Find a good surgeon}

Cancer of the oesophagus is a depressing condition with a poor survival rate. Having recently lost a colleague from the disease, I am well aware of the limitations of treatment, but depression leads to nihilism, and we may be able to do better.

Overall only about one in 20 patients with oesophageal cancer will be alive after five years. With such a dismal prospect why should they be expected to put up with complicated and painful treatment? Surely palliation is all that should be offered? The answer is that better results may almost certainly be achieved by better application of conventional methods of treatment (principally surgical resection) than is often the case in day to day practice.

Surgical resection of the oesophagus is risky. In 1980 a review of publications from around the world showed an average postoperative mortality of $29 \%$-hardly likely to inspire confidence. ${ }^{\prime}$ Many surgeons knew that they were doing better than this and so took up their pens. Today the average in published reports is $10-15 \%$ and getting lower. ${ }^{2}$ Reports of mortality below $5 \%$ are not uncommon..$^{+8}$ Surgical skill is an important factor: there is no place for the occasional oesophagectomist in the management of this cancer.

Saeger et al reported a decrease in mortality from $36 \%$ to $7 \%$ in a single hospital over 14 years. ${ }^{10}$ That such a large reduction in operative mortality may also improve overall survival from the disease has been documented in Australia by Morstyn et al. ${ }^{11} \mathrm{~A}$ recent study from Nottingham has shown the sort of results that may reasonably be expected with a $10 \%$ mortality: the five year survival in those surviving resection for squamous lesions was $36 \%$ but for adenocarcinomas only $3 \% .^{2}$ This is less than average: $12 \%$ would be more representative, but patients with adenocarcinomas fare less well in most series because of more advanced disease at presentation.

No form of adjuvant treatment increases the cure rate after resection of the oesophagus. Randomised studies have shown no benefit from either preoperative ${ }^{1213}$ or postoperative radiotherapy ( $M$ Fok and $G$ Zeiton, fourth world congress of the International Society for Diseases of the Oesophagus, Chicago, 1989). The response to chemotherapy for squamous carcinomas has improved enormously, with a 53\% response rate to a combination of cisplatin, vindesine, and bleomycin. ${ }^{14}$ A median duration of response of seven months in patients with advanced disease suggests that this line of treatment might be clinically useful in some patients with recurrent or inoperable disease. There is no evidence, however, that chemotherapy combined with resection improves outcome, but the final results of clinical trials are still awaited.

What about alternatives to surgery? Pearson reported a five year survival of $19 \%$ with radiotherapy as the primary treatment of squamous lesions. ${ }^{15}$ These results have often been quoted but never equalled. Probably a better indicator of what is likely to be achieved is the five year survival of $8 \cdot 3 \%$ reported from Manchester. ${ }^{16}$ Radiotherapy does, however, have an advantage in treating cancer of the cervical oesophagus because laryngectomy may be avoided.

Unfortunately palliation is all that is possible in at least half and possibly nearer two thirds of all cases, either because the patients are old and frail or because of advanced disease. Dysphagia may be greatly relieved in most cases without much risk. Endoscopic intubation, ${ }^{17}$ laser therapy,,$^{18}$ intraluminal radiotherapy (brachytherapy), ${ }^{19}$ and diathermy ${ }^{20}$ are the methods most commonly used. The choice depends to a large extent on local facilities and skill. Although they each have their particular advantages and disadvantages, all are capable of relieving dysphagia in most cases.

No doubt the prospects for cure will improve, but it will be to drugs and molecular biology that we must look. At the moment the best advice for the patient with a cancer of the oesophagus is to find a good surgeon. If he can't remove the lesion endoscopic palliation is usually simple and effective.

Reader in Surgery,

JOHN BANCEWICZ

Hope Hospital, Salford M6 8HD

\footnotetext{
Earlam R, Cunha-Melo JR. Oesophageal squamous cell carcinoma. I. A critical review of surgery. BrF Surg 1980;67:381-90.

Salama FD, Leong YP. Resection for carcinoma of the oesophagus. I $R$ Coll Surg Edinh 1989.34:97-100.
} 